\title{
Experimental investigation of the effect of wind speed and wind direction on a solar chimney power plant
}

\author{
O. C. Aja, H. H. Al-Kayiem \& Z. A. Abdul Karim \\ Department of Mechanical Engineering, \\ Universiti Teknologi PETRONAS, Malaysia
}

\begin{abstract}
Wind has been reported to have adverse effect on the performance of traditional solar chimney power plants but no reference has been made on the wind effect on inclined solar chimneys. An experimental investigation on the effects of ambient wind speed and wind direction on the performance of a south facing inclined solar chimney power plant model is reported in this paper. The effect of ambient wind speed and direction on the system performance was analyzed and the results showed that for the south facing collector, wind speed and directions have strong effects on the plant performance. The wind speed was found to have considerable influence on the convective heat loss through the cover and the walls to the ambient. Considering the wind direction, it was found that the system performance was favoured when the wind direction is from south moving north while the performance is impaired when the wind direction is from east or west. The results also showed some performance degradation when the wind is from the north. The findings also revealed that the walls of the air flow channel of the system resist the wind from sweeping the hot air generated in the system out to the ambient. Based on the findings, the use of inlet guide vanes as wind breakers at the collector inlet of traditional solar chimney power plant can reduce the losses associated to the wind effect inside the collector. The wind breakers will channel the natural energy of the wind into the system and enhance the system performance.

Keywords: convective heat losses, open-solar-air collector, solar chimney power plant, solar energy, wind speed, wind direction, air velocity, system performance.
\end{abstract}




\section{Introduction}

In 2011, BP [1] reported the global energy need has been mitigated with about 86.91\% fossil fuels (oil, gas and coal), 4.91\% nuclear energy, 6.5\% hydropower, while only about $1.68 \%$ was supplied from other renewable energy sources (Geothermal, Solar, Wind, Wood and Waste). A recent report from BP [2] showed that the global energy consumption for 2012 increased by $2.06 \%$ of the energy consumed in 2011 and the total energy consumed was supplied from 86.94\% fossil fuels (oil, gas and coal), 4.50\% nuclear energy, 6.66\% hydropower, and $1.90 \%$ renewable energy sources. The report from BP [2] also indicated that depletion in the non renewable energy resources reserves. It is important to point out that the use of the non renewable emery resources (fossil fuels and nuclear) as fuel endanger the environment through emission of greenhouse gases (Al-Ghandoor et al. [3]). In the quest to sustain our environment for future generation, a more environmental friendly energy use is pertinent. Renewable energy is globally been promoted which solar energy conversion systems have received high promotions. One of the interesting solar energy technologies that can be used for commercial electricity generation is the solar chimney power plants (SCPP) (Pasumarthi and Sherif [4]).

The SCPP is a solar thermal electricity generation plant which converts the solar energy into electrical power in a complex heat transfer and fluid flow processes. A traditional solar chimney power plant consists of a circular transparent canopy raised a certain height above the ground with a chimney at its centre as shown in Figure 1. The chimney at the centre houses one or more turbine(s) located at its base. Radiation from the sun penetrates through the transparent canopy/roof and strikes the ground surface. The ground absorbs the solar energy and in turns transfers the thermal energy gained to the adjacent air. The warm air inside the greenhouse becomes less dense, rises and flows toward the central chimney. The kinetic energy in the air is converted to electrical energy using the wind turbine(s) and generators.

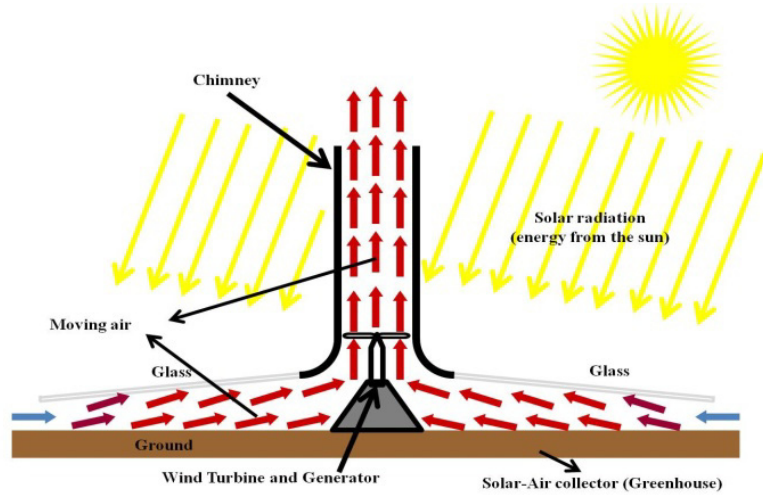

Figure 1: $\quad$ Schematic view of the solar chimney power plant. 
The SCPP operational principles are based on three technologies: greenhouse, chimney and turbine technologies (Schlaich [5]). This technology was first demonstrated by Prof Schlaich when he and his colleagues constructed a SCPP prototype in Manzanares, Spain. The prototype was experimented from 1982 to 1989 for about 15,000 hours and generated about $50 \mathrm{KW}$ of energy (Schlaich et al. [6]). The design model of the Manzanares SCPP prototype was presented in Haaf et al. [7] and the experimental results of the prototype was reported by Haaf [8]. Since the successful prove of the SCPP technology using the Manzanares prototype, several investigations on performance enhancement, designs, reduction of energy losses, integration of the SCPP with other process etc has been conducted by different researchers.

To enhance the power production during night times, Kreetz [9] investigated the use of water bags as heat storage medium. Pretorius [10] introduced the use of intermediate secondary roof to enhance heat storage in the soil of the collector. Pasumarthi and Sherif $[4,11]$ integrated collector with black canvas and black painted plate to improve the plant performance. Alrobaei [12] proposed the use of geothermal hot water pumped through pipes embedded in to the collector for thermal enhancement. Bilgen and Rheault [13] and Cao et al. $[14,15]$ investigated the use of mountain slope as collector/chimney. Davey [16] proposed hybrid solar pond and SCPP to enhance the system performance. Aja et al. [17-19] introduced and investigated hybrid process of SCPP with flue gas waste heat.

At the SCPP collector, the plant is faced with over $30 \%$ convective and conductive heat losses to the cover and ground respectively, Bernardes [20]. Convective heat loss impairs the performance of SCPP because the loss is completely irrecoverable while the conduction heat lost to the ground is stored and some percentage of the stored energy can be recovered and used for the night operation. Energy generated from SCPP wind turbine is dependent on the mass flow rate of the buoyant air which depends to a great extent on the air velocity at the collector inlet [21]. Ambient wind is the major cause of convective heat loss in SCPP [22, 23]. Investigation by Serag-Eldin [22] reveals that the wind velocity degrades the SCPP performance as a result of the wind sweeping the air in the system off the collector. Serag-Eldin [23] introduced the concept of controllable flaps to reduce the proportion of hot that is swept off the stack of SCPP by wind but did not consider the wind effect on the collector. Pretorius and Kröger [24, 25] investigated the effect of ambient environment on the performance of SCPP and the result inferred that the prevailing ambient winds at the location have considerable influence on the system and reduces the annual plant output by approximately $10 \%$ compared to the same plant under no wind conditions throughout the year. Similarly Pretorius [26] analyzed the effect of wind on a proposed SCPP in South Africa and reported that wind adversely affect the system performance. VanReken and Nenes [27] in their investigation inferred that cloud would probably form as a result of downwind thus causing shade over the collector area and reduce performance. Ming et al. [28] numerically simulated the effect of cross wind on the performance of SCPP and the results reveal two ways influence which inferred that when the wind is 
comparably weak (below $15 \mathrm{~m} / \mathrm{s}$ ), the system performance deteriorates while strong wind (above $15 \mathrm{~m} / \mathrm{s}$ ) will increase the mass flow rate and output power of the system. Du Preez and Kröger [29, 30] used turbulence numerical model to investigate the effect of wind on a cooling tower and it was found that the flows inside at on the inlet of the tower was affected by wind thus in order to minimize the wind effect, they introduced windbreak walls. Zhou et al. [31] mathematically correlated atmospheric crosswind and the air inside a SCPP with the assumption of the inflow air to be compressible. Their results inferred that strong wind velocity increases the air velocity in the system with large collector area; the system performance is reduced with wind effect. Recently, Ming et al. [32] numerical simulated SCPP with blockage surrounding the collector area giving some distance away from the collector inlet. Their investigation showed improvement and reduction in the effect of wind on the system. But the use of blockage in real practice will drastically increase the investment cost of the plant for commercial purposes. Similarly, if the distance between the collector inlet and the wall is not enough, it may also reduce the available supply of air to the system.

All the investigations on the wind effect were conducted numerically using the traditional SCPP geometry which the air inlet is open round the collector periphery with no consideration of the wind direction. This paper presents an experimental study on the effect of ambient wind on the performance of a south facing sloped SCPP which has its air inlet in one direction (facing due south).

\section{Experimental setup, instrumentation and procedure}

To experimentally study the effect of the ambient wind on the system performance, an experimental sloped SCPP was use. The sloped SCPP is a south facing SCPP which is composed of open solar air collector, air-chimney and turbine as shown in Figure 2. The open solar-air collector of the sloped SCPP is the greenhouse/heat exchanger of the plant where the energy from the sun is converted into thermal energy. The top surface of the open solar-air collector is made of transparent cover (acrylic glass) to allow the solar radiation to penetrate to the absorber plate. The system has two side-walls made of acrylic glass to allow solar radiation in to the channel even at sunrise and sunset (low elevation angle). The walls for the greenhouse support and hold the transparent cover over the absorber plate. The bottom of the open solar-air collector is the absorber plate (heat exchanger) where the solar radiation is absorbed and the heat energy gained is transferred to the working fluid (air). The absorber plate is made of aluminium sheet painted with flat black oil paint to increase the solar absorption of the surface. The open solar-air collector is designed to absorb the optimum available solar radiation at the location where the experiment was conducted $\left(4.39^{\circ} \mathrm{N}\right.$ and $100.98^{\circ} \mathrm{E}$ ) and also to enhance buoyancy and guide the air to the chimney. The collector has a total area of $3 \mathrm{~m}^{2}$ (width $1 \mathrm{~m}$ and length $3 \mathrm{~m}$ ).

The chimney acts as pressure tube through which the buoyant hot air generated in the solar air collector exits the system to the atmosphere. It is situated at the exit of the absorber plate, unlike the traditional SCPP which has 


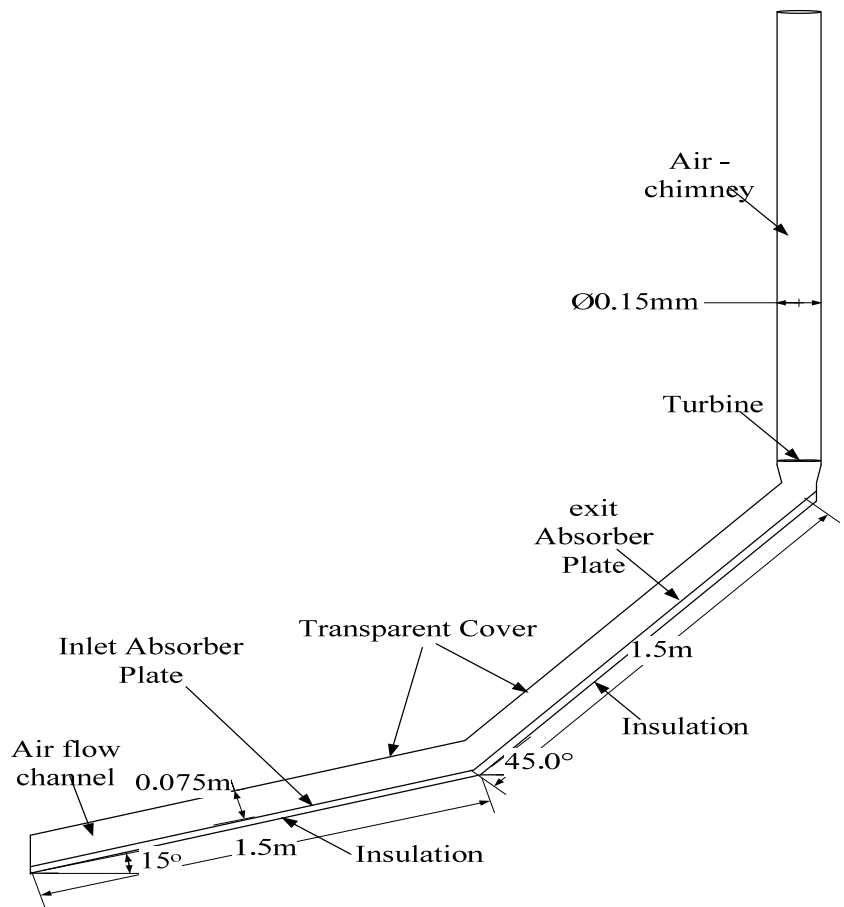

Figure 2: $\quad$ Schematic diagram of slope SCPP experimental test-rig.

its chimney at the centre of the solar air collector. The chimney of the experimental prototype was made of PVC pipe with internal diameter, $0.15 \mathrm{~m}$. The chimney height considered in the experimental investigation was $6 \mathrm{~m}$. At the base of the chimney is situated the wind turbine to convert the energy in the air into mechanical/electrical energy.

To prevent heat loss through the back of the system, the back was insulated with asbestos and plywood. The insulation was protected from weather effect using thing aluminium sheet (external). The thickness of the asbestos was $0.03 \mathrm{~m}$ while the plywood was $0.02 \mathrm{~m}$ thick.

To measure the parameters for the analysis of the system, the transparent cover was instrumented with 10 numbers of type $\mathrm{K}$ surface thermocouples to measure the temperature of the cover at different points from the inlet to the chimney connection point. The absorber plate was also instrumented with 11 numbers of type K surface thermocouples to measure the surface temperature. At the air flow channel 2 numbers of type K probe thermocouples were installed to measure the air temperature at the $15^{\circ}$ and $45^{\circ}$ tilted absorber plates. The chimney was instrumented with an air flow sensor to measure the air velocity at the chimney base and also a type $K$ probe thermocouple to measure the temperature of air before the turbine location. Above the position of the turbine in the chimney, the air temperature is measured using 4 numbers of type K probe thermocouples. The back insulation was instrumented with 6 numbers of type $\mathrm{K}$ 
surface thermocouples to measure the back temperature. The thermocouples wires where extended to lengthen the wire to the data logging point.

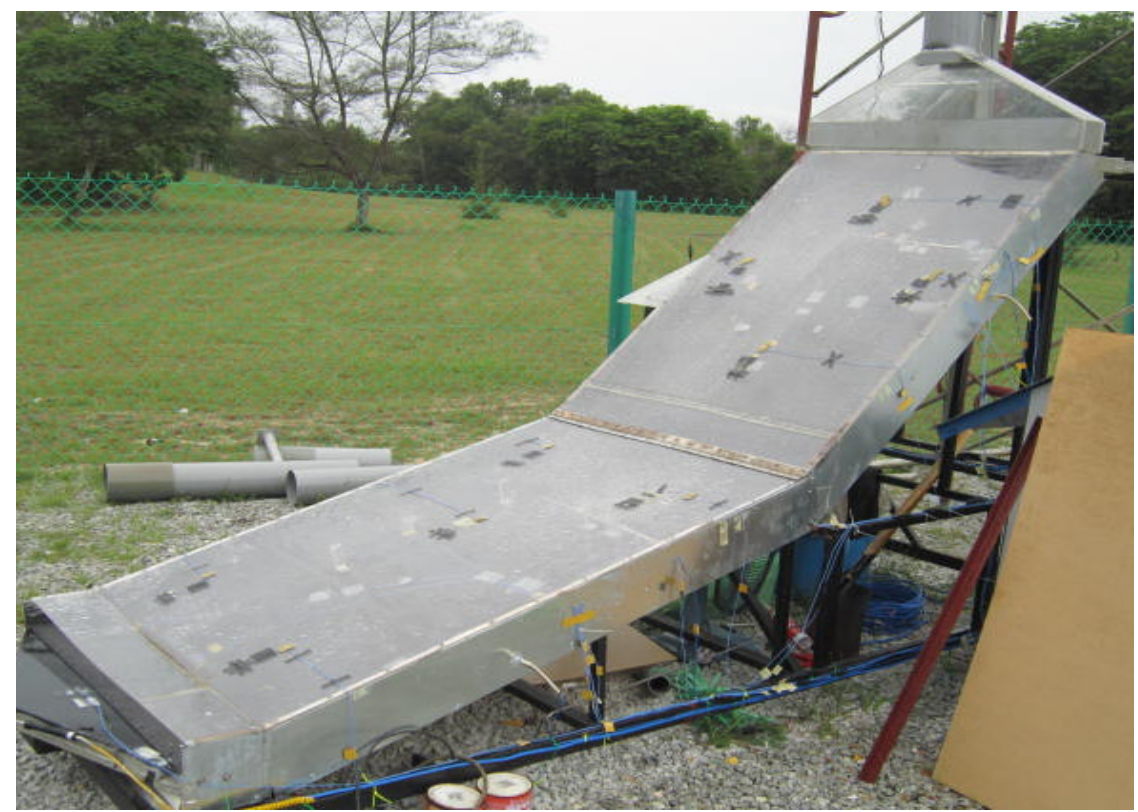

Figure 3: $\quad$ The experimental test rig Instrumentation.

The velocity of air at the chimney base was measured with the SCHMIDT air flow sensor - SS 20.260 (Figure 4). The air flow sensor was directly connected to data logger to measure capture the data per minute.

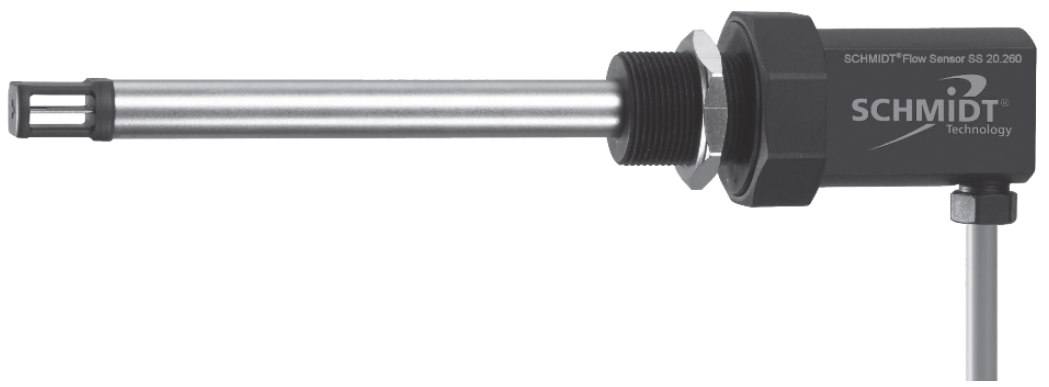

Figure 4: $\quad$ SCHMIDT air flow sensor - SS 20.260.

Two data loggers where used for the data collection, Graphtec 800 with 20 sensor connection slots and Fluke Hydra series II data logger with 20 sensor connection slots. The Graphtec 800 data logger was used to connect the SCHMIDT air flow sensor - SS 20.260 and some of the thermocouples and the data collected. 


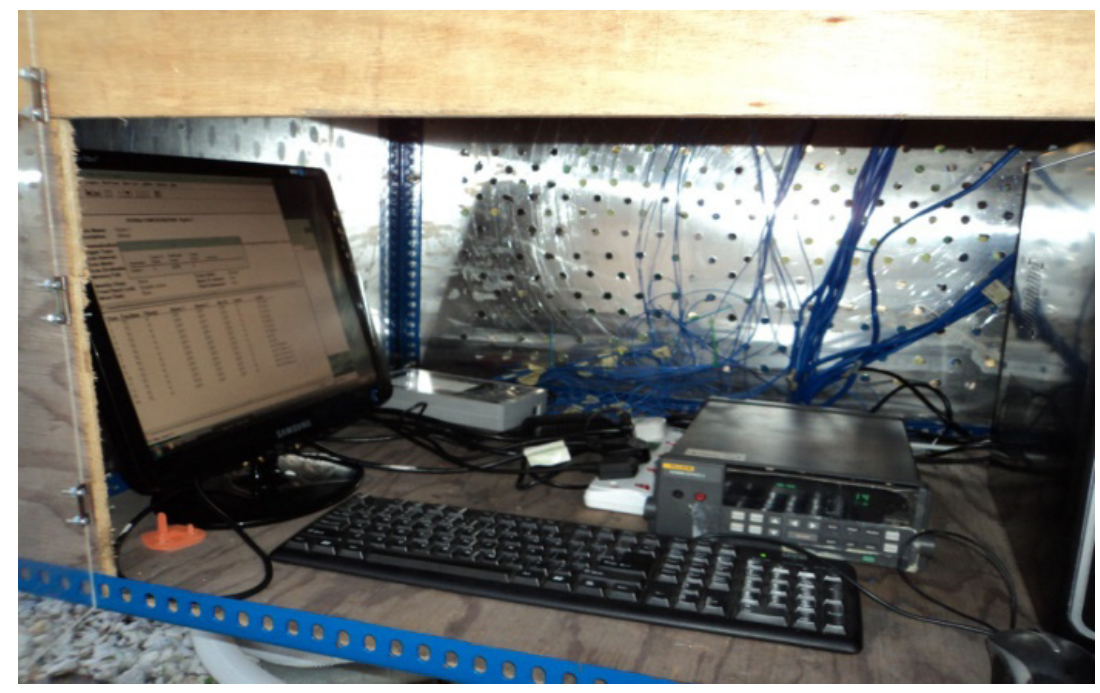

Figure 5: Data logging and sensor connections.

\section{Results analysis and discussions}

To be certain with the result of the investigation, the plant was investigated for 14 day using $6 \mathrm{~m}$ chimney attached at the collector exit. The ambient wind speed and wind directions were measured. At the location of study, it was found that during the month when the investigation was conducted, the wind directions were from north $\left(0^{\circ}\right)$ through east to south $\left(180^{\circ}\right)$. The temperature difference between the air in the system and the ambient air was found to be the driving force that produced the buoyancy effect and generated the velocity.

Considering the performance of the system under no wind condition, Figure 6 shows the average air velocity at the chimney base. It shows that the air velocity depend on the temperature difference.

Figure 8 shows the average angular wind direction for a whole day of investigation and the relationship to the effect of wind speed on the plant performance.

Looking at the result of Figure 8, it can be seen that when the wind direction is below $100^{\circ}$, the system experience a lot of losses which resulted in the drop in velocity of the system. This is because the wind sweeps over the transparent cover thereby causing loss of energy from the system to the ambient. This negative effect of the wind on the plant performance is in line with the reports of Pretorius [24] and Ming et al. [28, 32].

When the wind direction exceeds $110^{\circ}$, the wind velocities positively affect the plant performance. Some of the moving wind finds their way into the greenhouse. This is mostly experienced in the night. It can be inferred that for a walled solar air collector which opens at the base, for air inlet, wind velocity coming from the direction where the collector faces will receive enhancement as 


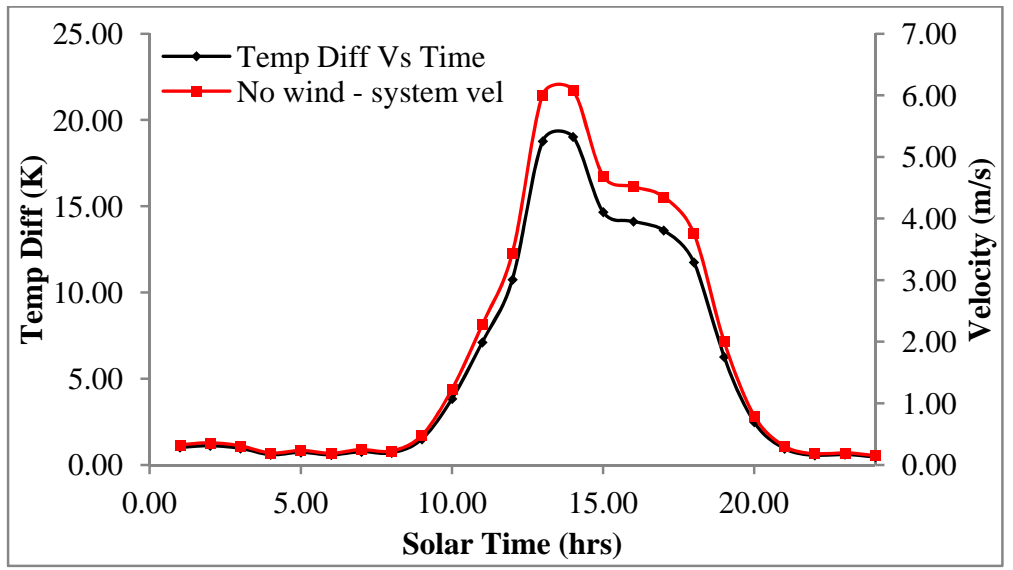

Figure 6: Temperature difference and system air velocity under no wind condition.

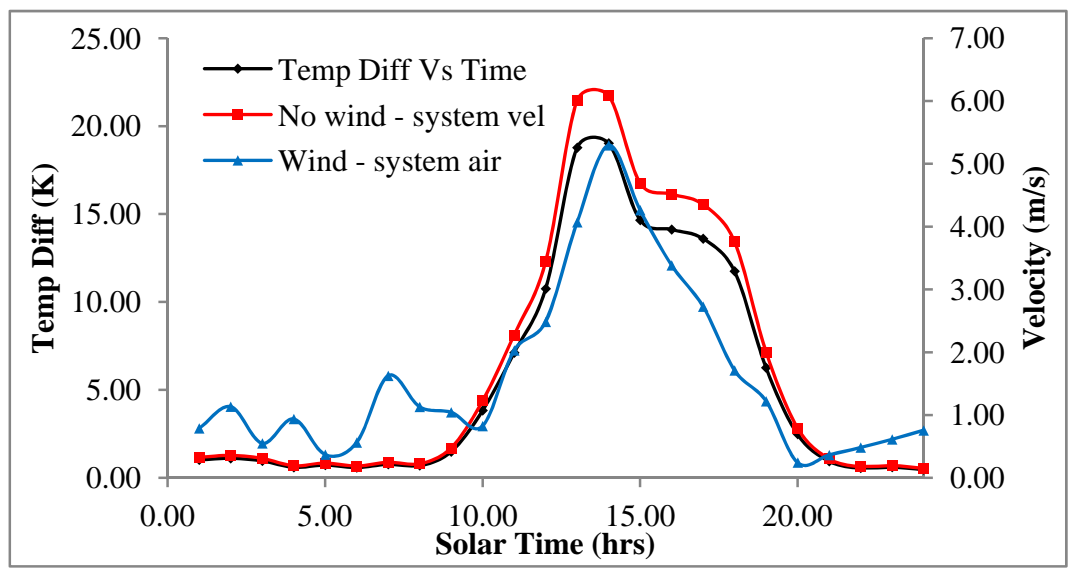

Figure 7: $\quad$ Temperature difference and system air velocity under no wind and windy conditions.

a result of the wind speed but when the wind comes $0^{\circ}, 90^{\circ}$ or $270^{\circ}$ from the inlet, the wind negatively affects the performance. In relation to the traditional solar chimney which is open round the periphery, as reported by Ming et al. [32], the wind negatively affect the system performance due to sweep of the hot air in the system out by the wind; they suggested the use of blockage round the power plant area which is considered very high cost. From the above results, the system performance can be improved by creating guide vanes that can guide the wind into the collector centre instead of the wind sweeping off the hot air; it will then enhance the air velocity and also the mass flow rate of the air in the system. 


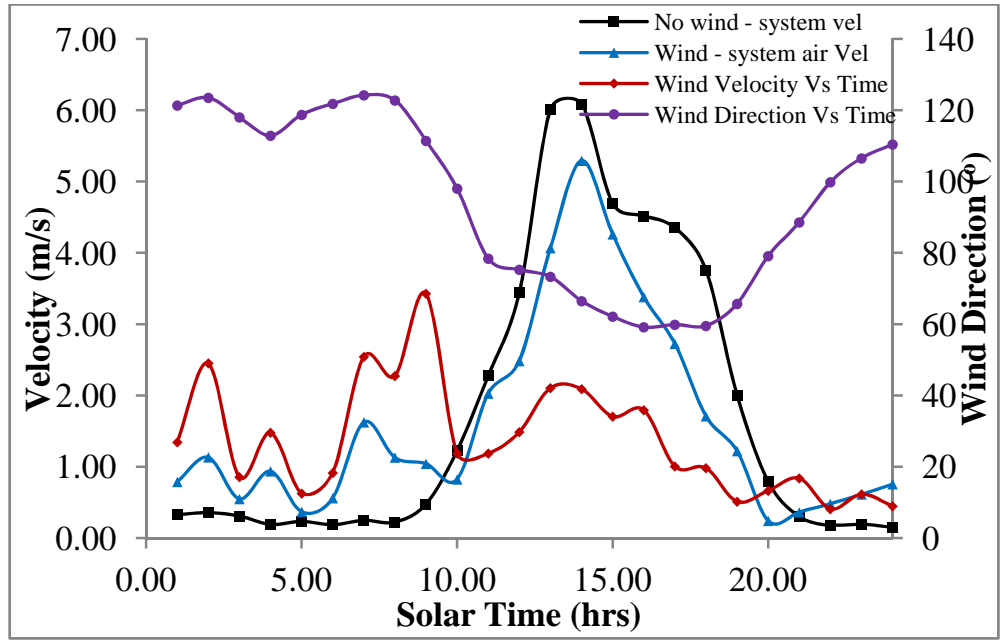

Figure 8: $\quad$ The effect of wind direction on the system air velocity.

\section{Conclusions}

The performance of a solar chimney power plant is affected by the wind velocity at the location. The wind direction is one important factor that has not been investigated on its effect on the plant performance. This work investigated the influence of wind speed and wind direction on the system air velocity. The system air velocity and mass flow rate are the major factors that controls the power output of a SCPP. With respect to the wind velocity, it was found that the wind velocity generally cause energy loss through the cover but for a south facing collector, it was found that the loss is higher when the wind direction is from the north, east or west but when the wind direction is from the south going north, the system performance is favoured due to flow of the wind into the collector. Based on this finding, the work suggest the use of inlet guide vanes at the periphery of traditional SCPP to reduce the heat loss from the collector as a result of the wind sweeping off the hot air in the collector

\section{Acknowledgement}

The authors would like to acknowledge Universiti Teknologi PETRONAS (UTP) for the technical and financial support to conduct the research under the internal research grant, STIRF, project 24/07.08.

\section{References}

[1] BP. BP Statistical Review of World Energy [Online]. Available: http://www.bp.com/assets/bp_internet/globalbp/globalbp_uk_english/report s_and_publications/statistical_energy_review_2011/STAGING/local_assets /pdf/statistical_review_of_world_energy_full_report_2012.pdf 
[2] BP. BP Statistical Review of World Energy [Online]. Available: http://www.bp.com/content/dam/bp/pdf/statisticalreview/statistical_review_of_world_energy_2013.pdf

[3] A. Al-Ghandoor, et al., "Electricity consumption and associated GHG emissions of the Jordanian industrial sector: Empirical analysis and future projection”, Energy Policy, vol. 36, pp. 258-267, 2008.

[4] N. Pasumarthi and S. Sherif, "Experimental and theoretical performance of a demonstration solar chimney model-Part I: mathematical model development”, International Journal of Energy Research, vol. 22, pp. 277288, 1998.

[5] J. Schlaich, The solar chimney: Electricity from the sun: Edition Axel Menges, 1995.

[6] J. Schlaich, et al., "Design of commercial solar updraft tower systems Utilization of solar induced convective flows for power generation", Journal of Solar Energy Engineering, Transactions of the ASME, vol. 127, pp. 117-124, 2005.

[7] W. Haaf, et al., "Solar chimneys part I: principle and construction of the pilot plant in Manzanares”, International Journal of Solar Energy, vol. 2, pp. 3-20, 1983.

[8] W. Haaf, "Solar chimneys, part II: preliminary test results from the Manzanares pilot plant”, International Journal of Solar Energy, vol. 2, pp. 141-161, 1984.

[9] H. Kreetz, "Theoretische Untersuchungen und Auslegung eines temporaren Wasserspeichers fur das Aufwindkraftwerk”, Diploma, Energieverfahrenstechnik und Umwandlungstechniken regenerativer Energien-EVUR, Technical University Berlin, Berlin, Germany, 1997.

[10] J. P. Pretorius, "Optimization and control of a large-scale Solar Chimney Power Plant”, Stellenbosch: University of Stellenbosch, 2007.

[11] N. Pasumarthi and S. Sherif, "Performance of a demonstration solar chimney model for power generation”, California State Univ, Sacramento, CA,(USA). pp. 203-240, 1997.

[12] H. Alrobaei, "Hybrid Geothermal/Solar Energy Technology For Power Generation”, 2007.

[13] E. Bilgen and J. Rheault, "Solar chimney power plants for high latitudes", Solar Energy, vol. 79, pp. 449-458, 2005.

[14] F. Cao, et al., "Performance analysis of conventional and sloped solar chimney power plants in China”, Applied Thermal Engineering, vol. 50, pp. 582-592, 2013.

[15] F. Cao, et al., "Simulation of a sloped solar chimney power plant in Lanzhou”, Energy Conversion and Management, vol. 52, pp. 2360-2366, 2011.

[16] R. C. Davey, "Device for generating electricity from solar power”, Australia Patent, 2008.

[17] O. C. Aja, et al., “Thermal field study and analysis in hybrid solar flue gas chimney power plant”, in National Postgraduate Conference (NPC), 2011, Universiti Teknologi Petronas, Tronoh, Perak, 2011, pp. 1-6. 
[18] O. C. Aja, et al., "Review on the enhancement techniques and introduction of an alternate enhancement technique of solar chimney power plant", Journal of Applied Sciences, vol. 11, pp. 1877-1884, 2011.

[19] O. C. Aja, et al., "Review on the Enhancement Techniques and a Novel Alternate of Solar Chimney Power Plant”. ICPER conference proceeding 2010 in International Conference on Production, Energy and Reliability (ICPER 2010), Kuala Lumpur, Malaysia, 2010.

[20] M. A. d. S. Bernardes, "Technische, ökonomische und ökologische Analyse von Aufwindkraftwerken”, Universitätsbibliothek, 2004.

[21] A. A. El-Haroun, "The effect of wind speed at the top of the tower on the performance and energy generated from thermosyphon solar turbine", International Journal of Solar Energy, vol. 22, pp. 9-18, 2002.

[22] M. A. Serag-Eldin, "Computing Flow in a Solar Chimney Plant Subject to Atmospheric Winds", in ASME 2004 Heat Transfer/Fluids Engineering Summer Conference, Charlotte, North Carolina, USA, 2004, pp. 1153-1162.

[23] M. Serag-Eldin, "Mitigating adverse wind effects on flow in solar chimney plants", in Proceedings of the 4th International Engineering Conference, Sharm El-Sheikh, 2004.

[24] J. P. Pretorius and D. G. Kröger, "The Influence of Environment on Solar Chimney Power Plant Performance”, $R$ \& D Journal, vol. 25, pp. 1-9, 2009.

[25] J. P. Pretorius and D. G. Kröger, "Solar chimney power plant performance", Journal of Solar Energy Engineering, Transactions of the ASME, vol. 128, pp. 302-311, 2006.

[26] J. P. Pretorius, "Solar tower power plant performance characteristics", Stellenbosch: University of Stellenbosch, 2004.

[27] T. M. VanReken and A. Nenes, "Cloud Formation in the Plumes of Solar Chimney Power Generation Facilities: A Modeling Study”, Journal of Solar Energy Engineering, vol. 131, p. 011009, 2009.

[28] T. Ming, et al., "Numerical analysis on the influence of ambient crosswind on the performance of solar updraft power plant system", Renewable and Sustainable Energy Reviews, vol. 16, pp. 5567-5583, 2012.

[29] A. F. du Preez and D. G. Kröger, "Effect of wind on performance of a drycooling tower", Heat Recovery Systems and CHP, vol. 13, pp. 139-146, 1993.

[30] A. F. du Preez and D. G. Kröger, "The effect of the heat exchanger arrangement and wind-break walls on the performance of natural draft drycooling towers subjected to cross-winds", Journal of Wind Engineering and Industrial Aerodynamics, vol. 58, pp. 293-303, 1995.

[31] X. Zhou, et al., "Influence of atmospheric cross flow on solar updraft tower inflow”, Energy, vol. 42, pp. 393-400, 2012.

[32] T. Ming, et al., "Numerical analysis on the solar updraft power plant system with a blockage”, Solar Energy, 2013. 